\title{
Illuminating the Invisible?
}

\author{
Michael Underwood \\ Population Ageing Associates \\ c/o 4 Stanefield \\ Letchworth Garden City \\ SG6 2SL \\ United Kingdom \\ Michael.Underwood@populationageing.co.uk
}

\begin{abstract}
The manifestations of inclusive design are currently somewhat invisible to a wide range of potential stakeholders and interested parties. The user may not be aware of the product features that make some products more suitable for their needs than others. The purchaser may not know what they should be looking for. The salesman may not have been briefed upon the needs of older or disabled people or how to sell to them. The marketing team may feel they cannot make overt reference to a product's inclusivity features for fear of alienating the core customer base. The product manager has little information on how many additional people will purchase his product if it is inclusively designed and hence has no objective basis on where to invest his development budget. And finally invisible to everyone, because as yet there seem to be relatively few successful examples in the real world.
\end{abstract}

These "invisibility" factors all make the promotion of inclusive design much more difficult to achieve. This paper will examine these factors in more detail, drawing upon research into the potential business opportunities for products and services intended for the larger numbers of older people in an ageing population; a major market opportunity in the developed world. A number of conclusions will be drawn as to how inclusive design might be made more visible in the implementation of high-tech products in the digital world.

Inclusive design, user-centred design, business benefits, case studies, stake-holders, older people, customers

\section{INTRODUCTION}

In an earlier paper [1], the author jointly proposed how a set of seven generic business drivers could be used to make the case for inclusive design. One of the conclusions of this earlier paper was that there was very little published information about the business benefits of adopting an inclusive design approach. This was in contrast to the growing literature on the importance of human factors and the adoption of user-centred design in the development of high-tech information and communication (ICT) products. Over the past twenty years, many books and papers have been produced showing the considerable cost savings that can be achieved by the involvement of the user at an early stage of the development process, compared with fixing products after they had been delivered to users. (It is interesting to note that as the cost of delivering software-based updates to users has fallen, many products with a high-tech component, such as cameras or video recorders, that can be reached via the internet or radio are now regularly updated after release to correct errors, make the products more usable or to add features in the face of competition.)

This framework for looking at inclusive design was applied during research into a book for business [2] on the market opportunities presented by an ageing population, something that is affecting much of the developed world. Here again, the authors became aware of the lack of business case studies that showed how companies had responded profitably to the opportunities presented, either through extending their mainstream markets by designing inclusive products, or by addressing the special needs of ageing.

This lack of business case studies relating to inclusive design in mainstream products for older consumers prompted the question WHY? This paper addresses that question, looking first at the nature of inclusive design itself, and secondly by looking at the roles played by different stakeholders and how inclusive design needs to be targeted at them.

\section{THE NATURE OF INCLUSIVE DESIGN}

For the purposes of this paper, the author will avoid the semantic distinctions between inclusive design, universal design, design for all and their derivatives. In essence, they are all trying to achieve the same objective, the design of products to be usable by as large a section of the population as possible. I will refer to them all as inclusive 
design. In practice, commercial considerations enter the decision about how large that section of the population can be. Designing products that are usable by every individual is both physically impossible and commercially unrealistic. Hence a balance has to be struck between what is socially desirable and commercially feasible.

There have been a number of driving forces behind inclusive design; one important driver being the move away from the medical model of disability to the social one, where the designer or supplier is considered to have failed if the user cannot use a product. It is no longer the fault of the user. Pursuing the social consequences has led a number of protagonists for inclusive design to add riders to the definition such as "without modification or additions". This derives from the perceived sensitivity of many people to be seen to be using products designed for people with impairments. This increases pressure on designers to create products in such a way as to minimise the visual (and auditory) impact of the inclusive features. Consequently, the inclusive design nature of the product becomes invisible to all those who do not know what to look for. Only those with training, or because they have a need that is addressed by the inclusive features in the product are able to see them.

So an interesting paradox lies at the heart of inclusive design. Products should be designed for everyone, but not look as if they have been designed for everyone. In other words the inclusive design features tend to be invisible. If the product looks as if it is intended for people with impairments, then those using it may feel stigmatised because they do use it. Likewise, those who do not have impairments do not wish to be stigmatised by being seen to be using such a product. This kind of argument has probably held up the appearance of inclusively designed products and is not just restricted to end-users or purchasers.

\section{PRODUCT AND MARKET MATURITY}

In immature businesses or markets with new technology, or where the technology is changing the dynamics of an existing market, it is often unrealistic to expect that ease-of-use is high on the priority list. Product managers are under pressure to get products into the market before competing suppliers; developers are under pressure to get the technology to work. The likely consequence is insufficient time or budget for significant user studies. As a result, relatively few first-generation high-tech products are easy to use. As the market develops, the perceived need and the actual need converge. Requirements that were not or could not be considered at initial release become more apparent as a product moves from being a specialist product through to being a mass-market product. Cameras, cars and computers all followed this trend over many years. Initially they were very expensive and had to be operated by specially trained people. Next they became the target of enthusiasts, who gained satisfaction from developing their skills in using the new technology. Finally, they became mass-market products that could be used by everyone with no knowledge of the basics of the product. The technical complexities of the product have to be hidden from the user in order to make them acceptable to the mass-market. As an example, consider those people who do not know how to turn off the flash on their digital cameras; they seem completely unaware that the flash on their camera will not illuminate the whole of an Olympic stadium!

The traditional marketing approach to new product introduction, whether in a new market or not, categorises the purchasers of products into five broad groups:

$\begin{array}{ll}\text { Innovators } & \text { the first } 5-10 \text { per cent who that adopt the product } \\ \text { Early adopters } & \text { the next } 10-15 \text { per cent } \\ \text { Early majority } & \text { the next } 30 \text { per cent } \\ \text { Late majority } & \text { the next } 30 \text { per cent } \\ \text { Laggards } & \text { the remaining } 20 \text { per cent }\end{array}$

Innovators and early adopters are usually considered to be crucial for launching new products. As purchasers, they are more likely to be concerned with purchasing the new product, showing other people they have the new product etc, than they are with issues such as the usability of the product. Older people, on the other hand, tend to be more concerned with value and quality (fitness for purpose), so consequently do not usually figure among the early adopters of a product, unless there is considerable advantage to them. In general, it follows that new products are not designed initially for older people; they are expected to follow in the early or late majority, when the technology is becoming more mature and the selling points no longer stress the novelty of technology, rather other aspects such as ease of use. The interesting question is whether demographic developments will change this in any way, as the relative numbers of younger people fall, thereby changing the characteristics of the early adopter market. Does this mean that new products will have to move faster up the usability curve on introduction to attract the larger numbers of older purchases earlier in the product life cycle than happens at present? The evidence that this might be happening - for instance with the introduction of digital television - is not encouraging [3].

The conclusion from this analysis is that inclusive design is unlikely to be seen (and hence is invisible) in new product types, as those people who appreciate or require ease-of-use are unlikely to be innovators or early adopters. Inclusive design features are more likely to appear in second or third generation products as the technology matures, sales are aimed at the majority users and companies need to compete against each other with something other than the technology that they will all have acquired by this stage of product evolution.

Given the way that products mature in the market, the creators of the web standards W3C and the WAI project are to be congratulated upon their foresight at an early stage in the life of the Internet to ensure that standards were 
established from the outset that would enable as many people as possible to benefit from the availability of information in all its forms on the internet, and not waiting for the normal cycle of product evolution to occur.

\section{STAKEHOLDERS VIEW OF INCLUSIVE DESIGN}

This section will look in more detail at the invisibility of inclusive design as it affects individual stakeholders throughout the product lifecycle starting with the end-users.

\subsection{Users}

Ease of use is well known for being difficult to measure, being a function of the user, the task, the product or application and the environment of use. The situation is further complicated for an individual user as the relative importance of different factors changes with time as they become expert in some aspects of use, whilst forgetting how to carry out less-frequently used tasks. As a consequence, complex products can only be assessed over an extended period of time; well after the purchase decision has been made. When an individual comes to purchase a replacement product, this experience with a previous product is invaluable in guiding the user as to what to look for. However, if one of the reasons for purchasing a replacement product is because the user is feeling the effects of impairments as a consequence of ageing, this prior knowledge is not enough. Their circumstances have changed and unless they are well informed they may be unaware of the product features they should be looking for to help with their impairment. In fact the product they have may well be suitable, if only they knew how to access the features on the product that were designed for such an eventuality.

So while the features may be present in a product that will enable the user to tailor the product to his/her requirements, those features may be invisible if the user manual itself is not easy to use. Ease of use extends to all aspects of the product as seen through the eyes of the user. The BT Big Button phone, which is one of the few documented examples of successful inclusive design, was also highly commended for the style of its user manual [4].

It is interesting to speculate on the reasons why many manufacturers selling products with a strong ICT component now make their product manuals available on the Internet. From the purchaser's perspective, it provides an ideal way of assessing the product functionality and usability before purchase. Did the manufacturer have this in mind, or was it done as a more cost-effective way of supplying manuals to people who had lost the original one or purchased the product without a manual via eBay?

\subsection{Purchasers}

There are two situations to consider here, depending upon whether or not the purchaser is the user. If the purchaser is the purchasing department of an organisation, are they aware of the needs of the individual users who will be using what they have purchased? Ease of use criteria are still relatively uncommon in procurement decisions in the UK; they are more important in the US where legislation governs the products themselves. It is therefore most unlikely that a purchasing department would be swayed by any arguments about particular products being usable by a wide range of users. The situation is likely change as more disabled people are employed and the number of older employees increases, both as a result of current and future legislation. Until then, purchasing departments will be unaware of inclusive design and what it can deliver.

Where the purchaser is the user the question is whether the information is available that enables them to make an informed choice. Many commercial products carry additional information that enables purchasers to assess hidden features of the products. For example, washing machines carry indications of how much energy they use, cars have to undergo safety tests, fuel consumption tests etc and this information can also be used by the salesperson to guide the purchase choice of the customer. However there are no standard independent usability criteria. Other than the tests carried out by organisations such as Which? and Ricability, there are limited sources of information that guide a purchaser on the potential suitability or ease-of-use of a product. The evidence from Ricability [5] is that the majority of mainstream products are difficult to use by people with impairments. Again we can conclude that inclusive design is invisible because it does not exist.

Furthermore, how many people are aware of the publications of Ricability? How many people subscribe to or use Which? Given the wide range of products that could be tested and the non-critical nature of usability compared with safety issues, it is most unlikely that we will see independent ease-of use badge marking on products. However, the magazines that do review mainstream products could do more to include usability in their testing and extending it to a wider range of users.

\subsection{Salespeople}

Next we have to consider where inclusively designed products are sold. Are they sold in the specialist shops where there is a good chance that the salespeople have received training in the relative merits of different products as they impact people with impairments? Or are they sold as mainstream products, in which case, there is a need for the sales force to be provided with the right kind of training material to enable the customer to make an informed choice. An inclusive sales approach is just as important a part of getting inclusively designed products to the customers as the design process itself. 
To date, much of the marketing of products for older people has been considered to be the province of the specialist suppliers and retailers. It has not been necessary for salespeople of mainstream products to be aware of the particular needs of older people, so again inclusive design has been invisible to the mainstream sales channel. Inclusive design is likely to become more established commercially as companies realise the market potential for products designed for a wider market. The sales channels will need to be developed; it will be necessary for salespeople to become aware of the kinds of features looked for by older people, so that they can sell the appropriate products with the relevant features to the customers needs. It will be in the interests of individual product manufacturers to see that information reaches the salespeople to ensure their inclusively designed products are promoted correctly.

\subsection{Marketing Manager}

The marketing manager has an interesting dilemma; how to promote his (inclusively designed) products in a way that appeals to the wider audience, but at the same time does not deter the larger core market for his product. Both the Ford Focus when it was first introduced, and the recently released new Focus were accompanied by articles in the press showing how the car had been designed to accommodate the needs of older drivers and passengers. But this information does not appear in the advertising or the sales brochures for the car. The inclusive design features were invisible. Perhaps this can be ascribed to the reluctance of the marketing team to create the wrong image for the car. Apparently, there is a saying in the motor trade that you can sell a young man's car to an old man, but you cannot sell an old man's car to a young man.

Vodaphone seem to be following the same route with their recently announced Vodaphone Simply product, a mobile phone with a limited set of facilities and a specially designed user interface. The early press coverage described the phone as addressing the essential requirements of mobile telephony, especially for older people, by dealing exclusively with voice communication and text messaging. They claimed this was in response to market research showing that older people in particular wanted simple, easy-to-use phones. This is at a time when more and more features are being crammed into mobile phones, largely for the benefit of younger customers, so that mobile phone operators can recover the massive investments they have made in $3 G$ mobile telephony. However, the first press advertisements for Vodaphone Simply make no mention of the older user, the person who might benefit most from the easy-to use features.

Indeed, the invisible way may be the "correct" way to sell inclusively designed products by emphasising the requirements that appeal to all users by focusing on the benefits that inclusive design brings, rather than concentrating on its features. Thus the car would be promoted on how easy it is to leave and enter. This approach offends no one, but the consequence is that inclusive design tends to become invisible.

The business implications of an ageing population are likely to be an important driver in the development and application of inclusive design, and one would expect to see older people featured more in advertising. However, it is hard to see this happening until the attitudes towards older people in this country change in a more positive direction. Unfortunately, most marketing departments tend to be staffed with younger people, the majority of whom do not yet have an appreciation of the consequences of minor impairments of advancing years. So inclusive design is invisible in the marketing department because most of the staff are personally unaware of the problems inclusive design addresses.

\subsection{Product Manager}

The product manager has to justify his budget to his superiors and then to decide how much should be assigned to each part of the process of getting the product to market. What return is he likely to get for the extra investment? How far is his share of the market likely to grow as a result of incorporating additional features into the product? What is the impact upon the selling price of the additional money required to develop the product and the provision of the additional features in the product itself?. How many people would be prepared to pay extra for inclusive features in the product? Market research may help, but generally there are few tools to help him make these decisions and very few case studies that he can use as a basis for his judgement. Experience from previous products may not be useful, because there are no controlled experiments that can be carried out to determine the consequences of inclusive design.

Where the product is a web-based product, there is the requirement under the Disability Discrimination Act that the web-site design should be accessible. As with other aspects of inclusive design, accessible web pages may not look obviously different on first inspection, so the manager is entitled to ask the question "What am I getting for my money?" Even if the site is accessible, how does he know how much of the success of the site is down to the fact that its design was accessible? He has no way of knowing, as it is impossible to separate out the accessibility features of the site from any other. The benefits of an inclusive approach are invisible.

\subsection{Senior Executive/ Board Member}

In the majority of companies, inclusive design is still invisible at the board level, largely because it is a potential solution to a problem that they are not yet addressing - the business implications and opportunities posed by an ageing customer population [6]. Awareness regarding older employees is much greater because of the pensions crisis and pending age discrimination in employment. Extending the addressable market of products by making 
their design inclusive is unlikely to have a dramatic effect upon company performance however, but the extra percentage points of market share may well be very valuable, especially in competitive markets, where a company is not the market leader. Of course, building an image of the company as being a supplier of inclusive, easy to use products may well convert it into being the market leader and boardrooms are concerned with the image and performance of the company as viewed by its customers and its investors.

In addition to producing returns for shareholders, wages and pensions to employees, products and services to consumers, company boardrooms increasingly have to respond to societal and environmental concerns and values - the area of corporate social responsibility. To date, much of the concern has been towards environmental and sustainability concerns and very few companies have made public pledges about ensuring their products are usable by all members of society. In making such a commitment however, it is essential that the company have in place the necessary processes to enable it to live up to such a statement. It is quite possible that a bandwagon effect could be created here, as companies respond to the challenges of the ageing population. This is not unlike the situation a few years ago when Volvo marketed their cars on the grounds that they were safer than others. Now safety testing has become an essential part of the testing of all new cars.

\section{REMOVING THE INVISIBILITY}

The previous sections have analysed some of the major difficulties in promoting the take-up of inclusive design, and argued that inclusive design, its features and its benefits are invisible across a wide range of stakeholders. The benefits of inclusive design are most obvious to the end-user, but the people who supply them with products need to be convinced that it is more than just a good thing. Without this evidence, there will be no investment in inclusively designed products and the end-users will not get the benefits.

Population ageing is likely to be one of the significant drivers of inclusive design as companies realise that youthdominated markets are potentially under threat from the growing numbers of relatively wealthy older people. However, the changes are relatively slow and may not give the rapid returns on investment that companies expect in high tech markets.

The earlier paper [1] described a range of potential business drivers for inclusive design along a stick and carrot continuum. (Legislation, standards, procurement, competitive threat, customer feedback, competitive advantage and brand image). Progress has been made in the strong 'stick' issues of legislation and standards but these usually set a lower threshold for adherence. Procurement rules are more of a driver in the US than in the UK. Competitive threat and customer feedback have not been major drivers so far because off the lack of companies who have invested in inclusive design. This will change as companies respond to changing demographics and social pressures. The opportunities for making a difference at this point lie with the carrot factors of competitive advantage and brand image.

Competitive advantage will only be gained if companies can see the business case for inclusive design. As noted at the beginning of this paper, there are very few well proper case studies of successful inclusive design. Although it may be difficult to isolate the factors in a rigorous manner, there is a lack of published material describing even the qualitative business consequences of taking an inclusive design approach. Too many supposed studies stop at the description of how it was done, not enough address the business consequences. Did the product make money for the manufacturer? Did it improve his market share? Without this kind of information, the commercial application of inclusive design will not progress. For the company executive, inclusive design is not an end in itself; it is a means to an end.

The other approach is through corporate social responsibility. Opportunities exist for companies to build their brand image by showing how their products are designed to be suitable for and usable by all members of society. In fact, the negative may be more powerful; showing that they do not unconsciously discriminate against certain members or groups of society. Statements of corporate social responsibility fulfil two purposes. They are used externally to build the image and standing of the company with investors and customers. No company is going to commit itself to such statements without ensuring that it has the means to deliver. The statements are also an indication of the way the company operates internally and can be used to drive forward the agenda for change within the organisation. The case for inclusive design needs to be made in all parts of an organisation and its supply chain to ensure that the benefits of inclusive design are visible to the user, the person with most to benefit.

\section{REFERENCES}

[1] Underwood M J and Metz D H. (2003) Seven Business Drivers of Inclusive Design, Proceedings of INCLUDE 2003 'Inclusive Design for Society and Business', Helen Hamlyn Research Centre, Royal College of Art, CD-ROM ISBN 1874175942 11, obtainable from Helen Hamlyn Research Centre (London)

Metz D H and Underwood M J. (2005) Older richer fitter, Age Concern (London)

[3] Klein J. (2004) Researching the Transition from Analogue to Digital Television for UK DTI (London)

(see www.fp.rdg.ac.uk/equal/Methodology/Jeremy_Klein2.pdf) 
[4] Lebbon C. (2003) Case Studies BT (see http://www.inclusivedesign.org.uk/pdf/Case019.pdf)

[5] Disability Rights Commission (2003) Inclusive Design - a report by Ricability. Report DRC/TP/IC. (Stratford upon Avon)

[6] SENIORWATCH (2002) Final Report (see www.empirica.biz/swa) 